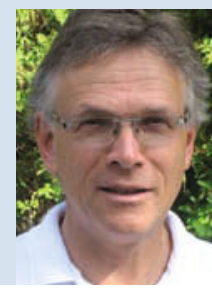

Dr. med.

Ulrich

Mutschler,

Hildesheim

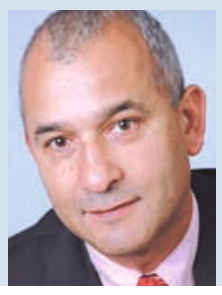

Prof. Dr. med. Tino F. Schwarz, Würzburg

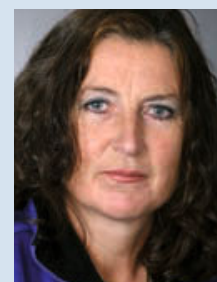

Dr. med.

Kirsten

Stollhoff,

Hamburg

\section{Kürzerer Nestschutz vor Masern bei geimpften Müttern}

Wie lange persistieren Masern-Antikörper der Mutter beim Kind und welchen Einfluss hat eine frühere Impfung der Mutter im Vergleich zu einer durchgemachten Infektion? Ein belgisches Autorenteam fand Antworten auf diese Fragen.

E ines der erklärten Ziele der WHO ist es, die durch Masern verursachte Morbidität zu eliminieren. Weltweit sind inzwischen gute Durchimpfungsraten erreicht, die Zahl der durch Masern verursachten Todesfälle ging in den Jahren 2000-2007 um 74\% zurück. Der primäre Schutz des Kindes vor einer MasernInfektion nach der Geburt ist durch die mütterlichen Antikörper bedingt. Würde ein Kind bereits in den ersten Lebenswochen gegen Masern geimpft, so könnten die mütterlichen Antikörper die Immunreaktion des Kindes unterdrücken.

Verschiedene Faktoren beeinflussen die Höhe der kindlichen Antikörper wie beispielsweise das Gestationsalter. Frühgeborene haben dabei niedrigere Antikörperspiegel. Auch der Grad der Durchimpfungsraten in einer Population hat eine große Bedeutung, da bei einer hohen Rate die Wahrscheinlichkeit einer natürlichen Boosterung unterbleibt. In vielen Industrieländern steigt das Durchschnittsalter der Mutter bei der Geburt des Kindes, damit nimmt auch der Abstand zur letzten mütterlichen MasernImpfung zu. Zudem ist im Zeitverlauf das Absinken der passiv auf das Kind übertragenen mütterlichen Antikörpertiter zu berücksichtigen.

In einer prospektiven Studie aus Belgien wurde bei Säuglingen die Konzen- tration der mütterlichen Masern-Antikörper untersucht. Insgesamt konnten 207 Mutter-Kind-Paare in die Studie aufgenommen werden, wobei 120 Frauen eine natürliche Infektion durchgemacht hatten und 87 Frauen geimpft worden waren. Serumproben der Mütter und Kinder wurden bis zu ein Jahr nach der Geburt untersucht.

Geimpfte Frauen zeigten signifikant niedrigere IgG-Konzentrationen als Frauen nach einer natürlicher Infektion. Die Titer betrugen $779 \mathrm{mIU} / \mathrm{ml}$ nach Impfung gegenüber $2.687 \mathrm{mIU} / \mathrm{ml}$ nach Infektion $(\mathrm{p}<0,001)$. Zwischen den mütterlichen und kindlichen IgG-Konzentrationen bestand bei der Geburt eine ausgeprägte Korrelation $(r=0,93)$. Die Titer der Kinder von geimpften Müttern lagen zu jedem Zeitpunkt der Nachbeobachtung signifikant unter denen von Kindern von Müttern mit durchgemachter Masern-Infektion $(\mathrm{p}<0,001)$.

Die mütterlichen Antikörper konnten bei Kindern der geimpften Frauen etwa einen Monat lang nachgewiesen werden. Im Vergleich dazu zeigten Säuglinge von Müttern nach natürlicher Infektion zwischen 2,6-3,8 Monate lang Antikörper. Nach sechs Monaten hatten fast alle Kinder die mütterlichen Antikörper verloren: 99\% der Impfgruppe und 95\% der Gruppe nach Infektion.

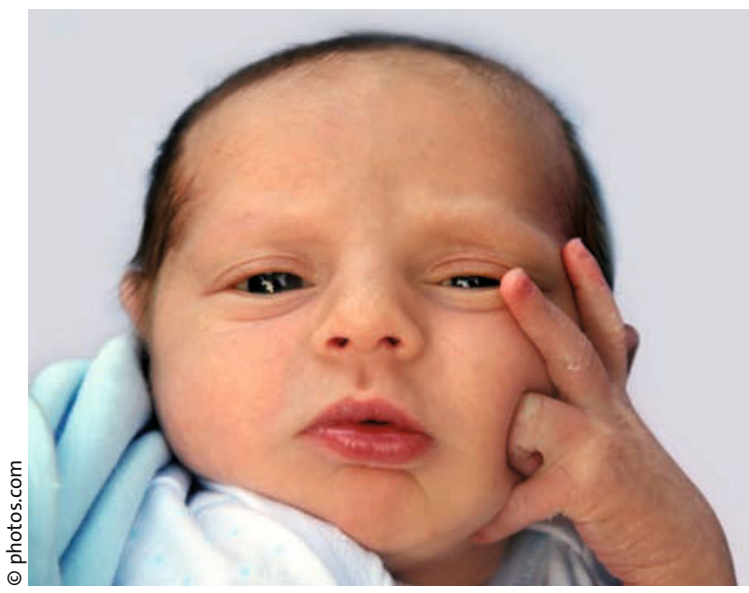

Masern-Antikörper oder nicht - das ist hier die Frage. Die mütterlichen Antikörper konnten bei Kindern von geimpften Frauen etwa einen Monat lang nachgewiesen werden.

Kommentar: Die Studie verdeutlicht, dass - entgegen bisherigen Annahmen - der Schutz von mütterlichen „Leihantikörpern" gegen Masern sowohl bei Kindern geimpfter Frauen wie auch nach natürlicher Infektion der Mutter bis zum sechsten Lebensmonat nahezu vollständig verloren geht. Die Kinder sind ab diesem Zeitpunkt bereits für Masern empfänglich. Die Studie unterstreicht die dringende Notwendigkeit der Masern-Impfung zum frühestmöglichen Zeitpunkt gemäß Impfkalender. Bei Reisen oder Kindern mit Migrationshintergrund sollte ggf. auch eine frühere Impfung erwogen werden. Prof. Dr. Tino F. Schwarz

Leuridan E et al. Early waning of maternal measles antibodies in the era of measles elimination: longitudinal study. BMJ 2010; 340: 01626 